\title{
Genetic aspects of athletic performance: the African runners phenomenon
}

This article was published in the following Dove Press journal:

Open Access Journal of Sports Medicine

20 May 2014

Number of times this article has been viewed

\author{
Rodrigo Luiz Vancini' \\ João Bosco Pesquero ${ }^{2}$ \\ Rafael Júlio Fachina ${ }^{3,4}$ \\ Marília dos Santos Andrade' \\ João Paulo Borin ${ }^{3}$ \\ Paulo César Montagner ${ }^{3}$ \\ Claudio Andre Barbosa \\ de Lira $^{5}$ \\ 'Centro de Educação Física e \\ Desportos, Universidade Federal do \\ Espírito Santo, Vitória, Espírito Santo, \\ Brazil; '2Departamento de Biofísica, \\ Universidade Federal de São Paulo, \\ São Paulo, Brazil; ${ }^{3}$ Departamento \\ de Ciência do Esporte, Faculdade \\ de Educação Física, Universidade \\ Estadual de Campinas, Campinas, \\ Brazil; ${ }^{4}$ Confederação Brasileira de \\ Basquetebol, Rio de Janeiro, Brazil; \\ ${ }^{5}$ Setor de Fisiologia Humana e do \\ Exercício, Faculdade de Educação \\ Física, Universidade Federal de Goiás, \\ Goiânia, Brazil
}

Correspondence: Claudio Andre Barbosa de Lira

Faculdade de Educação Física, Universidade Federal de Goiás,

Campus Samambaia, Caixa Postal I3I, CEP: 7400 I-970 Goiânia, Goiás, Brazil Tel +55 6481428455

Email andre.claudio@gmail.com

\begin{abstract}
The current dominance of African runners in long-distance running is an intriguing phenomenon that highlights the close relationship between genetics and physical performance. Many factors in the interesting interaction between genotype and phenotype (eg, high cardiorespiratory fitness, higher hemoglobin concentration, good metabolic efficiency, muscle fiber composition, enzyme profile, diet, altitude training, and psychological aspects) have been proposed in the attempt to explain the extraordinary success of these runners. Increasing evidence shows that genetics may be a determining factor in physical and athletic performance. But, could this also be true for African long-distance runners? Based on this question, this brief review proposed the role of genetic factors (mitochondrial deoxyribonucleic acid, the Y chromosome, and the angiotensin-converting enzyme and the alpha-actinin-3 genes) in the amazing athletic performance observed in African runners, especially the Kenyans and Ethiopians, despite their environmental constraints.
\end{abstract}

Keywords: genes, genotype, physical exercise, endurance runners

\section{Introduction}

In the 1980s, the international scene of medium- and long-distance running changed dramatically. Not so long ago, nearly all running events were dominated by European athletes. ${ }^{1}$ Of the top 20 worldwide, $50 \%$ were from Europe, and only $30 \%$ were from Africa. More recently, the percentage of European runners among the best in the world has fallen to $11 \%$, while that of African runners has jumped to $85 \%, 55 \%$ of whom are Kenyans. In fact, African runners now dominate in middle- and long-distance running, cross-country running, and street running. 2,3

The loss of supremacy by the European runners is not caused by their decreasing running speed. The reality is that the African runners are running faster. ${ }^{1}$ To give an overview, the Ethiopian, and Kenyan middle- and long-distance runners hold over $90 \%$ of all world records, and the first ten positions in the international ranking. ${ }^{3}$ Therefore, the question is: What makes the African runners, particularly Kenyans and Ethiopians, the best in the world?

In general, sports performance requires the integrated combination of many intrinsic (genetic, biological, etc), and extrinsic factors (exposure to the stimulus, environment, nutrition, technical-tactical training techniques, sport specialization, competition, sociocultural and financial aspects, motivation, career management, scientific support, etc). Some of these are trainable (physiological, psychological, and biomechanical) and some are taught (technical and tactical), while others are beyond the control of athletes and coaches, such as chronological age and genetic factors. ${ }^{3-5}$ In fact, it has long been 
suggested that genetic background plays an important role in sporting potential, being responsible for determining the anthropometric, cardiovascular, and muscular characteristics of adaptation to physical training. ${ }^{5}$ This background causes some individuals to be better adapted to physical training (responsive individuals), others to show little physical aptitude, even despite training (poor responsiveness), and still others to be without athletic tendencies (unresponsive individuals)..$^{5-7}$

Several factors in the complex interaction between genotype and phenotype have been proposed to explain the particular success of African runners, or the "African runners phenomenon", including: genetic predisposition; high maximum oxygen uptake $\left(\mathrm{O}_{2} \max \right)$ values; highest concentration of hemoglobin; relatively high hematocrit; the development of good metabolic efficiency (based on somatotype characteristics); favorable muscle fiber composition; profile of oxidative enzymes; the traditional Kenyan/ Ethiopian diet; constant altitude training; and motivation to achieve economic success and social mobility. ${ }^{3,7}$ However, evidence for a genetic component in physical performance is mounting, and more than 200 identified genetic variants may contribute to the observed variations in physical fitness. ${ }^{3,8}$ Based on this, the purpose of this brief review was to show the potential importance of genetic factors in relation to the intriguing phenomenon of the athletic performance observed in African runners.

\section{Genetic studies on African athletes}

The genetic inheritance of about 20,000 genes defines each of us as human beings. However, there is substantial variation among the individual human genomes that relates to the replication of genetic sequences and alterations in individual pairs. This variation is common - it has been suggested there may be approximately ten million single nucleotide polymorphisms (SNPs). ${ }^{9}$ Additionally, all of the variations in human characteristics (or phenotypes) result from the interaction between the genotype and environmental stimuli. For example, muscle and consequently physical performance is strongly influenced by the type of the muscle fibers (lean body mass composition), size of the muscle fibers, type of innervation, and blood flow. In this context, the muscle performance response to exercise training is dynamic, and genetic factors account for 50 to $80 \%$ of the interindividual variation. ${ }^{10}$

Until recently, no study directly investigated the role of genetics in the superior performance by African long-distance runners. Initial studies on Ethiopian and Kenyan athletes investigated mitochondrial deoxyribonucleic acid (mtDNA) and the $\mathrm{Y}$ chromosome: the first is deoxyribonucleic acid (DNA) located in the mitochondrion, while the $\mathrm{Y}$ chromosome is responsible for determining sex..$^{11,12}$ Accordingly, it was suggested that mtDNA polymorphisms influence the variation in humans' aerobic performance since these encode different subunits of the oxidative phosphorylation enzymatic complex. ${ }^{11}$

The mtDNA is maternally inherited, thus offering a unique opportunity to explore the maternal lineage. mtDNA only changes with the rise of new mutations, resulting in the accumulation of complex mutations linked to strains from different branches of a single ancestor's descendants. ${ }^{13}$ This is associated with the "Mitochondrial Eve", the name by which the latest common ancestor of all living humans is known. Thus, it is possible to create a detailed phylogeny, ie, determine the ancestral relationships among species and individuals, to explore the degree of relatedness from the maternal lineage of people, beyond the phenotypes of interest. ${ }^{2}$ Each branch of the phylogenetic tree is known as a haplogroup: a series of alleles at specific locations on a chromosome. Therefore, the haplotypes grouping generates specific easily comparable units of genealogical information that provide useful levels of predictability. When found in other parts of the world, the haplogroups can be used as indicators of recent migrations. ${ }^{14}$

Recently a cohort mtDNA analysis of the elite Kenyan and Ethiopian runners was performed. ${ }^{11,12}$ Cohorts are groups of people with a period event in common. Contrary to previous assumptions, these runners were not restricted to just one area of the phylogenetic tree; rather, the athletes showed a wide distribution of haplogroups, similar to the general population in Kenya and Ethiopia. These findings do not support the idea of a role for mtDNA variants in the sporting success of East African athletes in aerobic endurance events. The findings also contradict the idea that these elite runners are a genetically privileged group, at least with respect to the mtDNA. In fact, some of the Ethiopian athletes share a more recent mtDNA common ancestor with many Europeans. Similar results have also been observed among Kenyan runners. ${ }^{11,12}$ These findings did not confirm the hypothesis that Ethiopian and Kenyan populations have remained genetically isolated in East Africa, showing instead, that they have undergone "human migration events" estimated to have occurred, based on mtDNA studies, between 150,000 and 250,000 years ago. ${ }^{2,12}$

These findings are supported by analysis of the $\mathrm{Y}$ chromosome haplogroup distribution in elite Ethiopian athletes. The Y chromosome may be considered as the male 
equivalent of mtDNA. Although elite Ethiopian athletes have the same variation in $\mathrm{Y}$ chromosome haplogroups as the general population, some have been shown to be significantly more common in the athletes. The frequency of haplogroups has recently been evaluated in a Kenyan cohort study. ${ }^{15}$ If the same haplogroups were under- or overrepresented, this would provide strong evidence for a biological effect of the Y chromosome on running performance. However, despite the discovery of a potential Y chromosome effect on performance during aerobic endurance tests, study results showed diversity levels similar to those found in the mtDNA studies, meaning that a significant number of the genetically screened athletes had acquired part of their male ancestry outside Africa, sometime during the "human migration events".
Collectively, the results of the Y chromosome and mtDNA studies did not provide genetic evidence that supports the biological basis of racial differences in the sporting performance of African runners. ${ }^{3,15}$

Further studies have attempted to discover other candidate genes to explain the success of African runners. It was hypothesized that the genetic polymorphisms of interest are causal variants. To date, only two of the candidate genes that explain this phenomenon of human performance have been investigated: angiotensin converting enzyme (ACE), and alpha-actinin-3 (ACTN3) $)^{2,11,16-18}$ (Figure 1).

With regard to the $A C E$ gene, a polymorphism of insertion (I) is associated with lower levels of ACE than with deletion (D). ${ }^{16}$ In general, the I-allele from this gene

A

\section{ACE gene polymorphism}

Evaluate the presence or absence of $A C E$ gene variants in intron 16 of chromosome 17

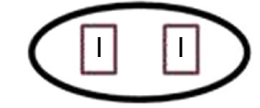

II allele

$\downarrow$

Lower levels of ACE

$\downarrow$

Greater

cardiorespiratory

fitness and tolerance to altitude

$\downarrow$

Higher performance in endurance running

B

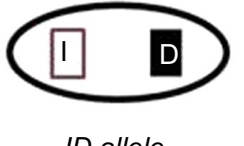

ID allele<smiles>CCC</smiles>

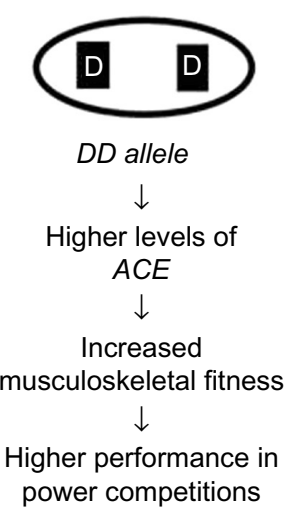

power competitions

\section{ACTN3 gene polymorphism}

Evaluate the presence or absence of a variant in the ACTN3 gene, known as $R 577 X$, present on chromosome 11, to assess the status of the elite athlete
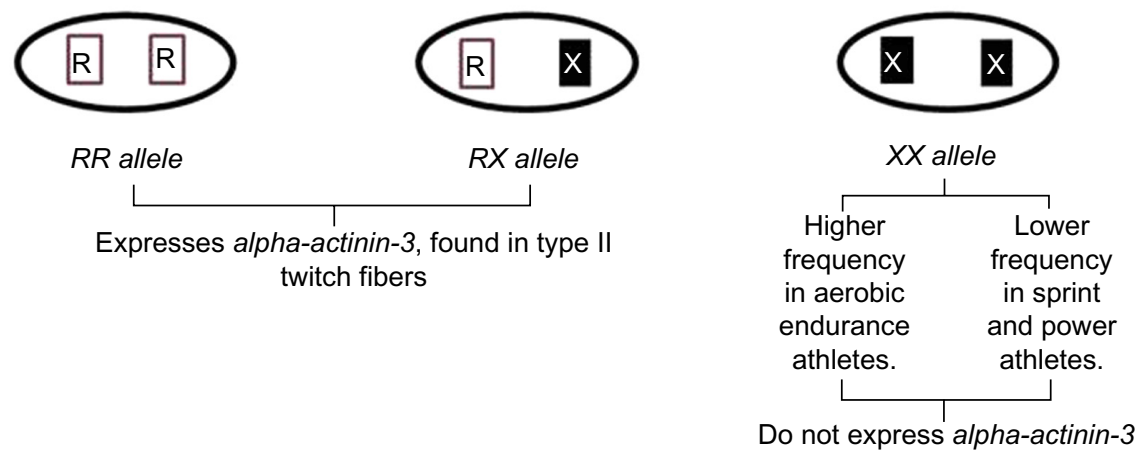

Figure I Genes associated with elite athletic performance.

Notes: (A) ACE gene polymorphism. Researchers have investigated the presence or absence of a variant in intron 16 of chromosome I7 on the ACE gene. (B) ACTN3 gene polymorphism. The presence or absence of the variant R577X, on chromosome II in the ACTN3 gene, was studied in relation to the status of elite athletes. Data taken from Wilber RL et al, Scott RA, et al, Rankinen T, et al, Arden Nk, et al and Lippi G et al. 3,4,8,10,25

Abbreviations: $A C E$, angiotensin converting enzyme; ACTN3, alpha-actinin-3; D, deletion; I, insertion. 
has been associated with performance during aerobic endurance tests, ${ }^{16}$ and the trainability of cardiorespiratory fitness, reflected by maximal oxygen uptake, determined by the ASSL1 gene and 21 SNPs. ${ }^{5}$ Meanwhile, the D-allele has been associated with performance during power tests, ${ }^{3}$ for which the heredity contribution may vary from $46 \%$ to $84 \% .{ }^{5}$ Interestingly, the I-allele has also been associated with high-altitude tolerance, making it an ideal candidate gene to investigate in East African athletes, given the possibility that regular training and constant living at higher altitudes could partially explain their sporting success. ${ }^{8,15,19}$ However, once again, there were no significant differences in I or D allele frequency between the Kenyan and Ethiopian athletes and the general population in their respective localities.

Given the different levels of linkage disequilibrium (nonrandom association of alleles) between Caucasians and Africans, it made sense that the addition of a potentially causal ACE variant (A22982G genotype) should be tested. However, no significant differences in the frequency of the A22982G genotype have been found between the Kenyan and Ethiopian athletes and the general population. ${ }^{16,17}$ In fact, in one study, $29 \%$ of subjects in the control group and only $17 \%$ of the international level Kenyan athletes had the "AA" genotype (always found in combination with "II" in Caucasians), which is supposedly beneficial to performance in tests of aerobic endurance. While the influence of the $A C E$ genotype on performance in aerobic endurance tests continues to be controversial, there is no scientific evidence for the variation in the $A C E$ gene that would explain the sporting success enjoyed by African athletes in long-distance running. ${ }^{3}$

The ACTN3 gene is another candidate gene that has been studied in African elite runners. ${ }^{20}$ This gene has also been associated with highest level of physical performance and has been found with different frequencies in different populations. ${ }^{21}$ In particular, a strong association was found between the R577X variant from the ACTN3 gene and elite athletes in white Australian populations, with ACTN3 XX genotype deficiency being present with a lower frequency in sprint and power athletes, and with a slightly higher frequency in elite athletes specialized in aerobic endurance tests, compared with the control group. ${ }^{20}$ Again, there was no evidence of a possible association between the R577X polymorphism and performance in aerobic endurance tests by East African runners, ${ }^{18}$ thus suggesting that the $A C T N 3$ deficiency is not a determinant for the sporting success observed among African runners. ${ }^{3}$ Figure 1 schematically shows the role of the two candidate genes, $A C E$ and $A C T N 3$, associated with athletic performance.
In summary, the genotyping of two candidate genes to assess the phenomenal physical performance observed among African runners did not show them to be the determinants for the sporting success in medium- and long-distance running. However, in order to exclude the possibility of genetic factors being directly responsible for the Africans' performance, other studies need to be undertaken to investigate the frequency of variants from other nuclear candidate genes, in these specific cohorts. Furthermore, research in this area is moving toward the "age of genomics", ie, the simultaneous study of multiple genes as well as the whole genome, rather than focusing on single candidate genes. This may help in future to shed light on the intriguing issue of the exceptional sporting success of African runners. ${ }^{3,7,8,15}$

\section{Area's prospects and closing remarks}

There is strong evidence that the interaction between genetic and environmental factors may be responsible for most of the individual differences in response to physical training..$^{22,23}$ Thus, it is important to continue investigating the variations in DNA sequences in the general population.

A critical analysis of this unique phenomenon has shown that these athletes do not descend from a single isolated genetic profile. ${ }^{4}$ The data suggest that the genes most studied and associated with performance in aerobic endurance running ( $A C E$ and $A C T N 3$ ) do not seem to fully explain the success of these athletes. It seems unlikely that Africa is producing unique genotypes that cannot be found in other parts of the world. So far, the evidence shows that the subjects' phenotype (molded over time by several factors) seems to have greater influence than their genotype in their longdistance running success. ${ }^{4}$ While recognizing that this field of study is at an early stage of understanding, the available results show that the identified candidate genes for human performance neither determine nor exclude the possibility of athletic success. Although, the right choice of parents can help in the search for athletic success, this is not the deciding factor between success and failure in sport. ${ }^{4}$

It is to be borne in mind that extraordinary athletic achievements by certain populations are without doubt a successful combination of many different factors. It is unlikely, though, that the success of these elite athletes is the result of an SNP,, 24 instead it must be the result of a wide combination of advantageous genotypes. ${ }^{4}$ Additionally, genetic testing in sport, an area of growing interest, can assist researchers in identifying individuals with the ideal physiology and morphology for the practice of certain activities; in the detection of athletes with 
greater responsiveness/adaptation to physical training; and in the prevention of injuries and sudden death, an extremely tragic event when it comes to high-performance athletes. ${ }^{25}$ However, the traditional methods used in identifying sporting talent remain consistent and valid since athletic performance is highly complex and multifactorial. It is also possible that genetic profiling may fail to consider a crucial DNA variant or genetic factor that may be responsible for improvement in physical performance. $^{5}$

Finally, it is necessary to bear in mind that only a small percentage of individuals have the "genetic background" and physical characteristics for athletic success. Not all these individuals will train, and only a small percentage of those who do will become elite athletes.

\section{Disclosure}

The authors report no conflicts of interest in this work.

\section{References}

1. Matthews P. Athletics'87: International Track And Field Annual. London: Simon and Schuster; 1987.

2. Larsen HB. Kenyan dominance in distance running. Comp Biochem Physiol A Mol Integr Physiol. 2003;136(1):161-170.

3. Wilber RL, Pitsiladis YP. Kenyan and Ethiopian distance runners: what makes them so good? Int J Sports Physiol Perform. 2012;7(2):92-102.

4. Scott RA, Pitsiladis YP. Genotypes and distance running: clues from Africa. Sports Med. 2007;37(4-5):424-427.

5. Tucker R, Collins M. What makes champions? A review of the relative contribution of genes and training to sporting success. Br J Sports Med. 2012;46(8):555-561.

6. Bouchard C, Dionne FT, Simoneau JA, Boulay MR. Genetics of aerobic and anaerobic performances. Exerc Sport Sci Rev. 1992;20:27-58.

7. Skinner JS. Do genes determine champions? Sports Science Exchange. 2001. Available from: http://www.iahsaa.org/Sports_Medicine_Wellness/ Performance/GSSI-Do_Genes_Determine_Champions.pdf. Accessed: May 2, 2014.

8. Rankinen T, Bray MS, Hagberg JM, et al. The human gene map for performance and health-related fitness phenotypes: the 2005 update. Med Sci Sports Exerc. 2006;38(11):1863-1888.

9. Goldstein DB, Cavalleri GL. Genomics: understanding human diversity. Nature. 2005;437(7063):1241-1242.
10. Arden NK, Spector TD. Genetic influences on muscle strength, lean body mass, and bone mineral density: a twin study. J Bone Miner Res. 1997;12(12):2076-2081.

11. Scott RA, Wilson RH, Goodwin WH, et al. Mitochondrial DNA lineages of elite Ethiopian athletes. Comp Biochem Physiol B Biochem Mol Biol. 2005;140(3):497-503.

12. Scott RA, Fuku N, Onywera VO, et al. Mitochondrial haplogroups associated with elite Kenyan athlete status. Med Sci Sports Exerc. 2009;41(1):123-128.

13. Atkinson QD, Gray RD, Drummond AJ. Bayesian coalescent inference of major human mitochondrial DNA haplogroup expansions in Africa. Proc Biol Sci. 2009;276(1655):367-373.

14. Salas A, Richards M, De la Fe T, et al. The making of the African mtDNA landscape. Am J Hum Genet. 2002;71(5):1082-1111.

15. Onywera VO, Scott RA, Boit MK, Pitsiladis YP. Demographic characteristics of elite Kenyan endurance runners. J Sports Sci. 2006;24(4):415-422.

16. Scott RA, Moran C, Wilson RH, et al. No association between Angiotensin Converting Enzyme (ACE) gene variation and endurance athlete status in Kenyans. Comp Biochem Physiol A Mol Integr Physiol. 2005;141(2):169-175.

17. Ash GI, Scott RA, Deason M, et al. No association between ACE gene variation and endurance athlete status in Ethiopians. Med Sci Sports Exerc. 2011;43(4):590-597.

18. Yang N, MacArthur DG, Wolde B, et al. The ACTN3 R577X polymorphism in East and West African athletes. Med Sci Sports Exerc. 2007;39(11):1985-1988.

19. Montgomery HE, Marshall R, Hemingway H, et al. Human gene for physical performance. Nature. 1998;393(6682):221-222.

20. Yang N, MacArthurDG, Gulbin JP, et al. ACTN3 genotype is associated with human elite athletic performance. Am J Hum Genet. 2003;73(3):627-631.

21. Mills M, Yang N, Weinberger R, et al. Differential expression of the actin-binding proteins, alpha-actinin-2 and -3 , in different species: implications for the evolution of functional redundancy. Hum Mol Genet. 2001;10(13):1335-1346.

22. Noakes TD, Myburgh KH, Schall R. Peak treadmill running velocity during the $\mathrm{VO}_{2}$ max test predicts running performance. J Sports Sci. 1990;8(1):35-45.

23. Tucker R, Santos-Concejero J, Collins M. The genetic basis for elite running performance. Br J Sports Med. 2013;47(9):545-549.

24. Pitsiladis YP, Scott R. Essay: The makings of the perfect athlete. Lancet. 2005;366 Suppl 1:S16-S17.

25. Lippi G, Longo UG, Maffulli N. Genetics and sports. Br Med Bull. 2010;93:27-47.
Open Access Journal of Sports Medicine

\section{Publish your work in this journal}

Open Access Journal of Sports Medicine is an international, peer-reviewed, open access journal publishing original research, reports, reviews and commentaries on all areas of sports medicine. The manuscript management system is completely online and includes a very quick and fair peer-review system.

\section{Dovepress}

Visit http://www.dovepress.com/testimonials.php to read real quotes from published authors. 